\title{
Response to Sheppard, C. Atoll Rim Expansion or Erosion in Diego Garcia Atoll, Indian Ocean? Comment on Hamylton, S.; East, H. A Geospatial Appraisal of Ecological and Geomorphic Change on Diego Garcia Atoll, Chagos Islands (British Indian Ocean Territory). Remote Sens. 2012, 4, 3444-3461
}

\section{Sarah Hamylton ${ }^{1} *$ and Holly East ${ }^{2}$}

1 School of Earth and Environmental Sciences, University of Wollongong, Wollongong, NSW 2522, Australia

2 Geography, College of Life and Environmental Sciences, University of Exeter, Exeter EX4 4RJ, UK; E-Mail: hke201@exeter.ac.uk

* Author to whom correspondence should be addressed; E-Mail: shamylto@uow.edu.au; Tel.: +61-2-4221-3589; Fax: +61-2-4221-4250.

Received: 13 March 2014 / Accepted: 17 March 2014 / Published: 19 March 2014

We welcome Sheppard's comments on our recent assessment of both ecological and geomorphic change at Diego Garcia Atoll in the central Indian Ocean [1]. Whilst our assessment incorporated numerous aspects of change, including movements of the lagoon rim shorelines, changes in the terrestrial vegetation on the lagoon rim and amendments to the bathymetry of the lagoon basin through dredging activities [2], this comment solely addresses the estimates of shoreline change. Here we make some brief remarks relating to this shoreline assessment of Diego Garcia and elaborate on some of the complexities of the geomorphic processes that underpin shoreline dynamics. These complexities have important implications for understanding reef island shoreline dynamics, both at this site and globally.

The contrast between our estimations of shoreline change at Diego Garcia and Sheppard's in situ observations appears to be overstated. Sheppard provided eight independent photorecords of his inter-annual observations for inclusion in our study ([3]) with which moderate correspondence was found when compared to our findings [2]. Four photographs exhibiting erosion were also associated with erosion in analysis of rim width transects. The remaining four photo records suggested no shoreline change, but our measurements suggested that rim widths had eroded over the longer 38-year period. Thus, our study [2] appears to indicate a greater amount of erosion than Sheppard's photographic evidence. Indeed, the wider study reported both erosion and accretion across 26 and 43 
transects respectively. A large proportion of those accretion sites are known to accurately report shoreline expansion due to the construction of the military facility.

We acknowledge the accuracy limitations of the comparison between the Stoddart (1967) map [4] and the recent satellite image. Unfortunately it is often the case that historical maps and aerial photographs represent the only available record of past reef island shorelines and, while these are of differing scales and quality [5] they offer the best opportunity available for determining reef island change over time [6]. Thus, as is frequently the case in analyses of reef island change, our study [2] sought to provide the best possible assessment of change given the available information. We calculate the additional margin of error associated with the small scale $(1: 125,000)$ of the historic map to be $20 \mathrm{~m}$, not the "more than 30 metres" claimed. This disparity may arise because Sheppard has cited a different map (Figure 31 from [4]) as the source of the baseline map: we used the map that was independently georeferenced by David Stoddart, on which shorelines are sketched with finer cartographic pens (Figure 2 from [4]). We make no judgment on the accuracy of Stoddart's maps because very little detail is provided on how these were made, other than that Stoddart's surveys were undertaken by tape and compass traverse with errors in measurement distances of $<1 \%$.

As 31 of the 43 transects for which accretion was reported fall outside the adjusted margin of error, we believe that our assessment [2] remains a useful indication of accretionary dynamics around several sections of the atoll rim. We provide here a new Figure 1 illustrating the results of a revised assessment of shoreline change incorporating only estimates falling outside the wider margin of error of $20.75 \mathrm{~m}$. We also draw attention to the earlier comments from David Stoddart that begin his descriptions of sand dunes on the aggrading coasts of Diego Garcia, and for which the full sentence reads: "while most of the seaward and lagoonward coasts of Diego Garcia are slightly retreating, as shown by the presence of erosion ramps and cliffing, sectors totalling about $17 \mathrm{~km}$ possess coastal dune belts" ([2], p. 15). Woodroffe [7] provides profiles of these dunes at Diego Garcia and describes similar ones on the coasts of other Chagos islands, including Brother, Danger and Egmont. These are observed at other Indo-Pacific atolls, including Cocos (Keeling), the Maldives, Kiribati and Tuvalu and are interpreted as a product of persistent winds in exposed locations [8].

Alongshore sediment transfer is also likely to play a significant role in shoreline dynamics. For example, at the northeastern narrow rim section, our evidence indicates that sediment is moving along the narrow section of the eastern side of the atoll to accumulate on the northern side of Cust Point. Similarly, there is a broad trend of sediment movement in a northerly direction along the south-western narrow rim between Pointe Marianne and Barachois Sylvain, which agrees with Stoddart's observations and lends support to our study [4]. Rather than implying erosion, alongshore fluxes of reef island material dominate under a transport regime in which the site-specific relationship between wave energy and sediment calibre prevent stable deposition [9].

We believe that it is an oversimplification to claim that the atoll rim of Diego Garcia is either "expanding", or "eroding". Variable rim dynamics incorporate both erosion and accretion around different atoll aspects, which themselves are a function of varying local environmental controls (e.g., incident wave energy). These alter shoreline configuration and elevation, resulting in spatially heterogeneous atoll rims [7]. Such heterogeneity is evident around the lagoon rim in the distinction between "narrow" and "normal" atoll rim types [2,4]. Narrow rims (45-250 m wide) represent geomorphologically recent and unstable links between older land areas that are often subject to along 
shore sediment transport and common breaching. Normal rims represent some of the oldest and most stable land portions of the atoll rim (average width $500 \mathrm{~m}$ ) and are formed by gradual accretion of the seaward beaches, with occasional washovers of sand raising the inland rim surface. Our study found statistically significant differences in the collective change measurements taken from these different rim segments, which indicate distinct localized sedimentary dynamics. Such differences with variation around aspects of the atoll rim caution against simplistic, overarching claims of "erosion" or "accretion" across the entire atoll.

Figure 1. Revised estimates of change in rim width (metres) between Stoddart's 1967 survey and the 2005 IKONOS satellite. Only points falling outside the margin of error are included.

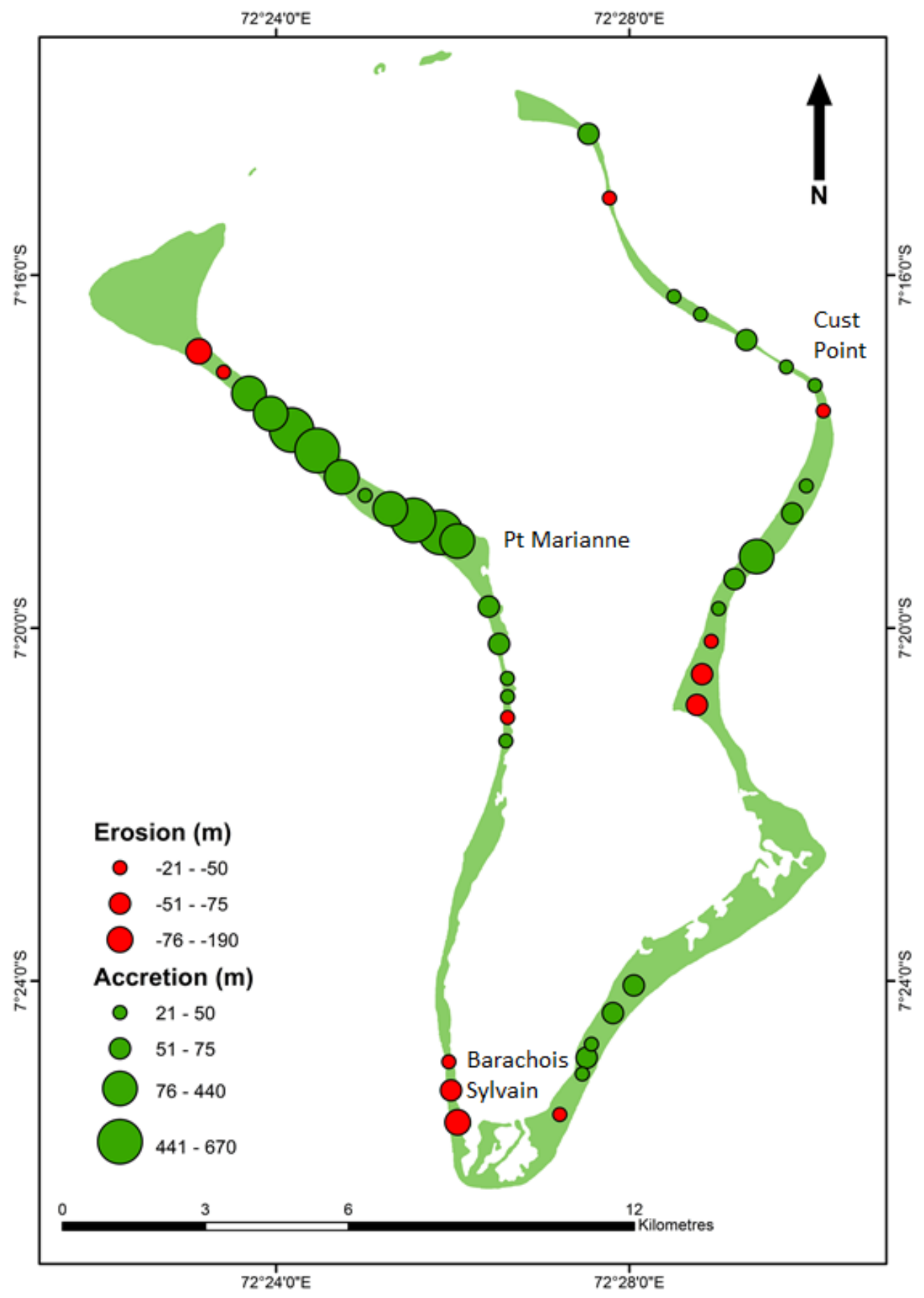


We wish to draw attention to some complexities of the geomorphic processes governing island dynamics, exemplified here and elsewhere in the literature on the response of reef islands to climate change. Firstly, seawater inundation is often incorrectly considered to be evidence of shoreline erosion. Overtopping is a natural process that supplies sediment to island surfaces [10]. It is the action of waves intruding onto reef islands that delivers sediment from the reef flat to the site of deposition at the island sink, thereby resulting in vertical and horizontal accretion. The consistent tendency to equate inundation with erosion disregards the fundamental role that hydrodynamics have in building and modifying reef islands. Secondly, sea level rise is often incorrectly interpreted as the primary control on shoreline stability of reef islands. Shoreline dynamics are actually governed by a more complex relationship between longer term sea level fluctuations, substrate gradients, accommodation space, relative wave energy and sediment supply [11,12]. Thirdly, projections of instability often treat reef islands as morphologically static landforms, but in actual fact they are adjusting to changes in local oceanographic conditions and sediment supply. Such adjustments include erosion, accretion, washover, shoreline realignments and island migration [11]. Available evidence suggests that the sedimentary island rim of Diego Garcia atoll is a spatially heterogeneous, dynamic landform in continual adjustment with its changing surroundings, rather than simply washing away.

Given the pressing nature of this research question for Diego Garcia, we encourage researchers who have the opportunity to visit this remote atoll to complement this analysis of maps and satellite imagery with a shoreline monitoring program including, for example, the establishment of in-situ marker horizons, surface elevation tables, video records of shoreline fluctuations and radiocarbon dating of historical island evolution. At minimal cost, such a program would provide a compelling, multifaceted investigation of shoreline change at Diego Garcia Atoll.

\section{References and Notes}

1. Sheppard, C. Atoll Rim Expansion or Erosion in Diego Garcia Atoll, Indian Ocean? Comment on Hamylton, S.; East, H. A geospatial appraisal of ecological and geomorphic change on Diego Garcia Atoll, Chagos Islands (British Indian Ocean Territory). Remote Sens. 2014, 6, 2463-2467.

2. Hamylton, S.; East, H. A geospatial appraisal of ecological and geomorphic change on Diego Garcia Atoll, Chagos Islands (British Indian Ocean Territory). Remote Sens. 2012, 4, 3444-3461.

3. Sheppard, C. Personal communication, 2012.

4. Stoddart, D.R. Geomorphology of Diego Garcia Atoll. Atoll Res. Bull. 1971, 149, 1-237.

5. Anders, F.J.; Byrnes, M.R. Accuracy of shoreline change rates as determined from maps and aerial photographs. Shore Beach 1991, 59, 17-26.

6. Webb, A.P.; Kench, P.S. The dynamic response of reef islands to sea-level rise: Evidence from multi-decadal analysis of island change in the Central Pacific. Global Planet. Change 2010, 72, 234-246.

7. Woodroffe, C.D. Reef-island topography and the vulnerability of atolls to sea-level rise. Global Planet. Change 2008, 62, 77-96.

8. Woodroffe, C.D.; McLean, R.F. Pleistocene morphology and Holocene emergence of Christmas (Kiritimati) Island, Pacific Ocean. Coral Reefs 1998, 17, 235-248. 
9. Mandlier, P.G.; Kench, P.S. Analytical modelling of wave refraction and convergence on coral reef platforms: Implications for island formation and stability. Geomorphology 2012, 159, 84-92.

10. Kench, P.S.; McLean, R.F.; Brander, R.W.; Nichol, S.L.; Smithers, S.G.; Ford, M.R.; Parnell, K.E.; Aslam, M. Geological effects of tsunami on mid-ocean atoll islands: The Maldives before and after the Sumatran tsunami. Geology 2006, 34, 177-180.

11. Kench, P.; Perry, C.; Spencer, T. Coral Reefs. In Geomorphology and Global Environmental Change; Slaymaker, O., Spencer, T., Embleton-Hamann, C., Eds.; Cambridge University Press: Cambridge, UK, 2009; pp. 180-213.

12. Cowell, P.J.; Thom, B.G. Morphodynamics of Coastal Evolution. In Coastal Evolution: Late Quaternary Shoreline Morphodynamics; Carter, R.W.G., Woodroffe, C.D., Eds.; Cambridge University Press: Cambridge, UK, 1994; pp. 33-86.

(C) 2014 by the authors; licensee MDPI, Basel, Switzerland. This article is an open access article distributed under the terms and conditions of the Creative Commons Attribution license (http://creativecommons.org/licenses/by/3.0/). 